\title{
从新城市主义到形态控制准则 美国城市地块形态控制理念与工具发展及启示
}

\author{
From New Urbanism to Form-based Code - Lessons Learnt from the US Experience of \\ Block Shape Control Concepts and Tools
}

章征涛 宋彦 丁国胜 李志明

Zhang Zhengtao, Song Yan, Ding Guosheng, Li Zhiming

\begin{abstract}
摘要: 城市蔓延是美国规划界急需解决的问题。针对城市无 序蔓延带来的一系列城市形态问题, 美国规划师们向物质 空间设计层面回归，先后提出新城市主义、精明准则、形 态控制准则等城市形态控制理念和工具。其中形态控制准 则是针对城市地块形态控制的工具。本文对美国城市形态 控制与调整工具的发展脉络以及相互联系进行分析; 对形 态控制准则进行详细阐述; 最后, 针对当前我国城市蔓延 问题初显, 及在城市形态控制工具不足等矛盾下, 从发展 理念、操作工具及行业发展三个层面提出建议。

Abstract: Urban sprawl is a challenge faced by the planning field in the US. To confront with a range of issues associated with sprawling urban form brought by urban sprawl, planners in the US have retreated to design tools of the physical environment and initiated concepts such as new urbanism, smart codes, and formbased codes, which is the tool to shape urban form at the site level. The article first describes the evolving trend of urban form tools, illustrates in detail the form-based codes, and lastly, provides policy suggestions to urban form tool in China from three perspectives including concepts, implementation and the development of the planning field.
\end{abstract}

关键词：城市地块形态控制工具；新城市主义； 形态控制准则

Keywords: Urban Block Shape Control Tool; New Urbanism; Form-based Code

作者: 章征涛, 博士, 注册城市规划师; 珠海市规划设计研究院 政府规划与城市设计研究中心, 副主任; 高级规划师 宋彦 (通信作者), 深圳大学城市规划系, 教授; 美国北 卡罗来纳大学城市规划系, 终身教授; 国际中国规划学会 (IACP) 第七届 (2017-2019) 主席

丁国胜, 博士, 湖南大学建筑学院助理教授, 硕士生导师, 健康城市研究室主任

李志明, 博士, 南京林业大学城市规划系系主任, 副教授

\section{引言}

可持续的城市形态和高品质的公共空间一向是规划师、建筑师 和景观设计师的理想, 而这很大程度上却依赖于城市形态控制工具 的发展。针对快速城市化时期大量的开发建设活动, 我国目前已经 形成以控制性详细规划为核心的开发控制体系, 并在引导和控制城 乡发展过程中扮演了重要角色。然而, 这一体系也广受批评, 其中 之一就是控制性详细规划对城市形态和空间的引导和控制难以达 到预期目的。比如, 由于控规的制定主要依赖于当地相应的技术标 准（而当地标准很多情况下又是参考国标）, 对城市形态和空间的 考虑不够周全, 往往造成尺度偏大、公共空间缺乏和丧失特色等 问题。为了解决这些问题, 近年来微观层面的城市设计得到快速 发展, 规划师们期望通过城市设计达到控制城市形态的目的。然而, 当前城市设计远未达到成为控制和调整城市形态工具的程度, 它 更加侧重于一种思考方式贯穿于城市规划的各阶段。因此, 开发 适合我国城市地块层面形态控制和调整工具仍然是当前规划界面 临的重要挑战。

美国城市蔓延已受到国内外规划界的广泛批评，成为可持续城市 形态的反面案例。许多文献显示造成这一局面的重要原因之一在于区 划制度 (zoning), 认为正是由于区划过于强调功能划分而不重视空间 和场所营造才导致普遍的城市蔓延, 并使得城市缺乏特色。基于此, 美国规划师们先后提出新城市主义、精明准则及形态控制准则等形态 控制理念或工具, 期望能够扭转区划带来的城市发展弊端, 形成一个 结构紧凑、尺度适宜、健康绿色的可持续城市形态。尽管我国与美国 国情、规划制度差异较大, 但在工具层面, 美国近些年形态控制发展 历程仍然对探索适合我国城市形态控制方法有所借鉴。

已有中文文献对新城市主义、精明准则和形态控制准则等单个 工具进行过介绍, 有利于国内规划师了解和熟悉这些工具。然而, 目前文献对于这些工具之间的内在联系和发展脉络缺乏深人探讨, 容易造成盲目借鉴和生搬硬套。为此, 本文拟对这些城市形态控制 
工具之间的发展脉络以及相互关系进行分析, 以弥补这方面 不足。

\section{1 城市形态控制工具的发展脉络和内涵}

\section{1 城市形态控制工具演化脉络}

美国区划在漫长的发展和调整过程中, 管制内容经历了 不断变迁和升级, 一系列新工具开始逐步纳人规划的管理和 控制当中，提升了区划综合应对城市问题和管制的灵活度 ${ }^{[1]}$ 。 美国传统欧几里得式的规划方式 (conventional zoning) 仅依 赖于条件性和功能性分区要求 ${ }^{1}$, 强调功能的分离, 导致几 乎每种用地类型都各自独立, 成为推动城市蔓延的内在动力。 不仅如此, 不同类型的居住分离, 更刺激了美国社区的分化 和隔离。随着传统区划问题越发明显, 区划改良工具也逐渐 出现。但就形态控制工具发展脉络而言, 最具代表性的是二 战以来试图以设计力量影响建成环境的新城市主义运动 ${ }^{[2]}$, 它倡导对现有区划进行全面检讨。基于 1980 年代初佛罗里 达州的规划设计案例, 安德烈斯 - 杜安尼 (Andres Duany) 和伊丽莎白・普莱特 - 齐伯克 (Elizabeth Plater-Zyberk) 夫妇 在 2003 年发布了《精明准则》(Smart Code)。2001 年, 卡罗 尔 - 怀恩特 (Carol Wyant) 提出了 “形态控制准则” (FBCs: Form-based Codes) 定义, 并催生了 2004 年非营利性的形态 准则协会（Form-based Codes Institute）的成立, 致力于形态 控制准则的研究和推广。

传统区划主要控制地块开发性质和开发强度, 属于功能 导向控制。它一般采用抽象数据, 以禁止式条文来明确禁 止的功能。换言之, 在缺少体量控制的前提下, 地块的强 度和密度等限制手段造成开发商有意避让, 形成 “火柴盒” 状建筑（图 1 左）。虽然规划师试图通过城市设计来改变这 种状况，但多落人地块外在景观塑造的“巢臼” (图 1 中)。 相对于传统区划的内容, 城市形态控制工具着重于控制微 观层面的建筑形式、建筑布局、市民活动空间等建成环境，
属于地块层面形态导向的控制 (图 1 右)。形态控制准则通 过法律、法规手段, 采用图文方式明确地块的形态。可以说, 城市形态控制工具的发展脉络反映出美国城市规划路径向 物质空间设计或曰空间形态的回归, 以此寻求改革城市功 能和空间感受。

\section{2 形态控制工具的内在关系和侧重点}

从形态控制工具自身发展看, 它重现和强化了物质空间 决定论思想。该思想源于现代主义运动, 旨在通过物质空间 营造良好环境, 解决社会、经济、环境等城市问题。同时, 它也推动了源于 18 世纪欧洲启蒙运动想要彻底摆脱历史羁 绊的空间规划实践, 形成了新建或重建整个城市或城市大部 分地区的欲望和冲动 ${ }^{[4]}$ 。1960 年代以后, 由于对理性主义 和功能主义的批判, 以及系统论思想的引人, 城市规划本身 对物质空间的侧重开始逐渐积累了相关学科的优势; 比如, 社会学、经济学和地理学也越来越关注城市、空间和土地 使用 ${ }^{[5]}$ 。此外, 对于规划实施的强调, 使规划更专注于行动, 而不仅仅是对规划构思或决策的重视, 随之而来的是关注公 共利益和多元协同, 倡导式规划、沟通式规划逐渐成为当时 乃至当前规划理论的主要 “范式” 之一 ${ }^{[4]}$ 。当然, 在这个规 划理论流变中 (物质化转向沟通化), 美国规划理论并没有 彻底抛弃物质空间设计, 仍始终坚持通过土地区划, 以法律 形态保障个人利益。至 1980 年代, 新城市主义兴起, 在批 评以现有土地分区为基础的物质形态方法的基础上, 它强调 需要完善和推动形态角度对空间的控制, 以此达到对人行为 的控制。比如, 新城市主义主张回归历史城镇的优秀传统, 致力于复兴和推动可步行、混合用途的社区, 即从多样性形 态要求检讨现有区划所带来的形态局限。简言之, 美国规划 理论发展本身始终坚持了物质形态的方法, 尽管这其中出现 了积累、迭代、综合的规划理论体系 ${ }^{[6]}$, 但是, 形态控制 (土 地使用）的内容却一直贯穿于整个规划理论脉络中, 呈现出

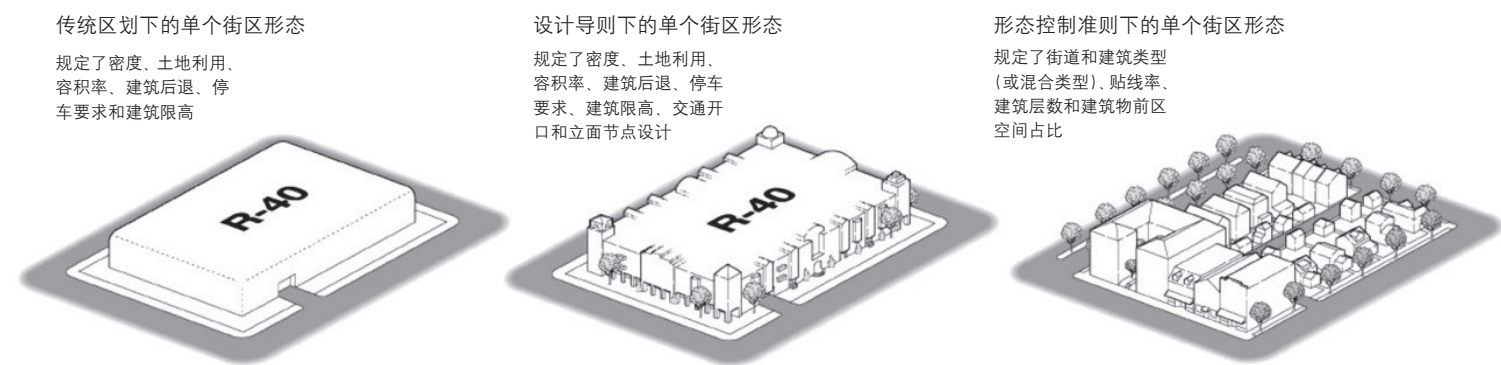

图 1 传统区划标准（左）、城市设计引导（中）、地块形态控制准则（右）对地块控制情况的对比 资料来源 : 参考文献 [3]

(1) 功能性要求指将城市划分为不同的区域, 各区域内有各自允许的土地使用类型, 主要包括居住、商业、工业; 条件性区划则规定地块的大小、 高度和退让红线距离等。 
一幅形态控制工具不断演变和丰富的画面。

新城市主义作为一种物质空间设计的理念, 为精明准则 和形态控制准则提供了理论基础, 也为后两者提供了行动框 架。比如, 新城市主义所倡导的步行化、混合土地用途等要 求都成为精明准则和形态控制准则的目标, 在准则中都对此 进行了较为完善的表述, 并体现在实施层面。需要强调的是, 新城市主义本身并不具有实际的工具性和实施性, 它更类似 于一种形态控制理念。精明准则偏重于区域和城市层面, 对 城市内的形态要素提出控制, 通过源自生态学的断面划定, 用 “形态过渡” 的方法来区分七种不同类型的城市形态。它 针对不同类型区域的建设特点和形式, 提出了一套如何将区 域性规划原理具体落实到每一个规划区内部的指标体系和形 态控制法则。形态控制准则, 在精明准则对区域和城市层面 控制要求的基础之上（其实在宏观层面我们可以将两者纳人 一套控制要求中), 重点是形成对地块 (建筑) 层面的控制 内容。它通过类型学的方式, 从各种建筑和公共空间的形态 出发, 通过横断面的校核, 抽取出不同分区关于公共空间和 建筑形态的标准, 配以示意图表达, 取代传统区划的抽象数 值。此外, 这种图像还具有法规属性, 通过可视化的表达, 相比文字表述更加简短精炼, 也更易于理解。

由于精明准则在横断面控制内容与形态准则存在部分内 容重叠, 都是通过断面形态来实现差异化的空间形态控制, 因此, 笔者在文中仅重点对新城市主义和形态控制准则进行 阐述, 不再累述精明准则。

\section{2 新城市主义理念}

\section{1 新城市主义的提出}

二战后, 伴随着小汽车的普及和公路的大规模建设, 美 国率先步人了郊区城市化加速阶段。对于崇尚自由的美国人 来说, 近郊住所 (suburban living) 成了大部分美国人的 “理 想环境”, 在当时被称为 “美国人的梦想”。在这种梦想的驱 动下, 大量中产阶级流向郊区。当然有些学者也指出, 或许 是出于对城市生活的恐惧和逃离 ${ }^{[7-9]}$, 推动城市居住方式和 空间形态演变的潜在动力。尤其在 1970 年代后, 出现了所 谓的“城市曼延” (urban sprawl)。城市蔓延不仅造成了交通 拥挤, 更对人们的社会生活造成了严重影响 ${ }^{[10-15]}$, 如城市内
部出现阶层和种族分化、郊区孤立等问题。

1993 年 10 月, 在美国亚历山大市召开的第一届 “新城 市主义代表大会”（CNU: Congress for the New Urbanism）标 志着 “新城市主义时代” 的正式来临。从其出发点看, 它认 为导致美国城市的一系列困境基于美国的汽车文化和现代主 义城市理论。因此, 新城市主义的核心观点认为, 汽车重构 了城市和社区, 并且成为城市蔓延的主要工具; 同时, 现代 主义思想又割裂了社会文化和传统, 试图营造一个同质、毫 无特色的城市和社区空间。因此, 新城市主义站在可持续 发展的立场之上, 提出步行尺度和回归传统的对策。正如 1996 年签署的《新城市主义宪章》(The Charter of the New Urbanism）所提倡的, 新城市主义主张恢复现有的中心城镇 和位于都市连绵区内的城镇, 将蔓延的郊区重新整理并配置 为多样化的、真正的邻里社区 ${ }^{[13]}$ 。

\section{2 新城市主义的内涵}

新城市主义的思想内涵非常丰富, 主要包括传统邻里 开发 (TND: Traditional Neighborhood Development)、公交 导向开发 (TOD: Transit-Oriented Development) ${ }^{1}$ 、城市村 庄和精明增长等建设模式 (表 1), 它们的特点都是提倡适 宜步行的邻里环境, 功能混合, 多样化的住宅, 高质量的 建筑和城市设计, 传统的邻里结构, 高密度, 精明的交通 体系, 可持续发展及高生活质量等 ${ }^{[15]}$ 。在彼得 - 卡尔索普 (Peter Calthorpe) 看来, 美国“新城市主义”主要指三件 事 : 第一是可步行的社区 (walkable community); 第二是多 样化 (diverse), 指新城市主义的社区应该包容宽泛的年龄 组、不同类型和收人水平的家庭等; 第三是人的尺度 (human

\section{表 1 新城市主义方式的原则比较}

\begin{tabular}{c|c|c|c|c}
\hline & 传统邻里开发 & 公交导向开发 & \multicolumn{1}{|c|}{ 城市村庄 } & \multicolumn{1}{|c}{ 精明增长 } \\
\hline 不同 & $\begin{array}{l}\text { 集中在地方或 } \\
\text { 集中在与区域 } \\
\text { 而典建筑上 }\end{array}$ & $\begin{array}{l}\text { 相连强调自足 (住宅 } \\
\text { 枢纽上 }\end{array}$ & $\begin{array}{l}\text { 在推进变革时增 } \\
\text { 和工作的混合) 和褐 } \\
\text { 色土地政府政策和各 } \\
\text { 再开发 }\end{array}$ & $\begin{array}{l}\text { 类优惠的政策 } \\
\text { 共同 } \\
\text { 元素 }\end{array}$ \\
$\begin{array}{l}\text { 混合使用、住宅类型的混合、紧楱的形式、可以步行的环境（步行 } 5 \text { 分钟, } \\
\text { 城市设计、中心区可供选择的交通模式、有吸引力的公共场所、高质量的 }\end{array}$ \\
\hline
\end{tabular}

资料来源 : 参考文献 [15]

(1) 传统邻里开发 (TND) 是在 1930 年代 “邻里单位” 社区规划模式的基础上提出的。重点在对传统城市邻里空间重塑, 打破现代城市体系中简 单的功能分区, 回归传统社区邻里生活方式, 强调交往空间、邻里单元和传统街坊的重要性。公交导向开发 (TOD) 是以区域性公交站点为中心, 以人步行的最大需求距离为设计半径, 将人们所需的各方面的设施和建筑都安排在这一设定半径中, 其目的是以公共交通取代私人汽车, 在宏 观设计层面减少环境污染。关于城市村庄 (urban villages)，英国的“城市村庄论坛”将其描述为“可持续的和相对自给自足的新开发”。该思 潮采用了许多传统街区设计的原则。在美国, 城市村庄有可能是公交导向开发枢纽的另一个名称, 这类公交导向开发枢纽可能是一个需要填充 的褐色场地, 或沿公交线路的边远地区新城镇的开发场地。精明增长 (smart growth) 则旨在促进地方归属感、自然文化资源保护、开发成本 和利益公平分布的社区规划、设计、开发和复兴。通过提供多种交通方式、多种就业、多样住宅, 精明增长能够促进近期和远期的生态完整性, 提高生活质量。 


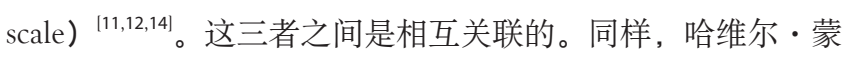
克鲁斯和瓜迪亚（Javier Monclus and Guardia）提出，新城市 主义具有六大主要特征 : 一个中心 ; 5 分钟路程的邻坊 ; 细 密的格状街道系统; 狭窄多用途的街道; 混合使用; 特殊 场所用于特殊建筑 ${ }^{[16]}$ 。总之, 新城市主义提倡创造和重建 丰富多样的、适于步行的、紧凑的、混合使用的社区，对 建筑环境进行重新整合, 形成完善的都市、城镇、乡村及 邻里单元。

此外, 《新城市主义宪章》还从区域、城镇和城区这三 个层面解读了新城市主义的规划理念, 以指导公共政策、开 发行为、城市规划和设计 ${ }^{[13]}$ 。(1) 区域层面考虑规划的宏观 性, 从大都市、城市和城镇视角, 认为区域规划必须跨越传 统的行政区界，建立一个合理的、易于分析的区域界定。它 还提出区域范围内的城市需要有一套综合的都市发展战略, 以求得区域的共同繁荣。此外, 区域内的城市应当有明确的 边界, 相邻市镇之间的土地应当被保留为开放空间——空地 或者农田。(2) 城镇层面主要从街区、区和走廊的角度出发, 强调清晰可辨的地区。它认为街区应是紧凑的、步行友好的、 混合使用的; 区通常以一种特定的单一功能为重点; 走廊则 是街区、区的连接, 包括林荫道、轨道、河流和园林小路。 （3）城区层面从地块、街道和建筑物角度出发, 提出街道 需要通过建筑物来体现一个连续的、易于识别的边界, 为人 们提供安全、舒适的步行和聚会的好地方。

\section{3 对新城市主义的批判}

“新城市主义” 这个概念的“新” 是相对于 18、19 世纪 工业革命浪潮导致的城市主义 (Urbanism) ${ }^{1}$ 而言的。新城 市主义的 “新” 正是试图对这种异化的都市生活方式提出一 种修正。但是, 在新城市主义的批评者看来, “新”成为笔伐 的对象。他们认为, 新城市主义理念不过是一种对传统的怀 旧和理论总结, 并将其称为 “新传统城市主义” (Neo-traditional Urbanism) ${ }^{[15,17-19]}$ 。虽然新城市主义者也承认他们无意创建 前所未有的奇思妙想, 但他们坚持传统中有许多持续有生命 力的东西值得继承。但与此同时, 新城市主义在理论上也不 可避免地带上一些和传统理论一样的缺陷 ${ }^{[15,20-22]}$ : 在认识上, 新城市主义仍用欧洲传统城市的眼光看待当代城市的发展演 变; 在方法上, 新城市主义的错误在于将目前问题所表现出 的现象的反面作为解决问题的关键 ; 在意识形态上, 新城市 主义在反对基于现代主义的城市观的同时却陷人了与它同样 的困境, 即其在本质上仍然坚持了乌托邦式的美好承诺, 以
自信的理性将某种尺度和秩序强加给城市生活的每一个领 域, 只不过一个表现得激进, 另一个表现得保守。

因此, 在新城市主义的实践中, 虽然它创造了比以往郊 区更好的物质环境, 但许多结果都与其初衷背道而驰, 和现 代主义城市一样无法兑现自己的承诺。首先, 它没有阻止郊 区的无序蔓延, 反而成了帮凶; 其次, 新城市主义的实践并 没有减少私人汽车的使用, 还要尽量安排停车位; 第三, 新 城市主义者以高房价高密度取悦了开发商的同时却使打破种 族、收人造成的隔离成为空谈 ${ }^{[23]}$ 。作为对新城市主义的批评 者代表者, 格兰特 (Grant) 则总结了新城市主义的五个问 题。(1) 可支付性 : 并不能创造所说的混合的多元社区, 因 为修建费用高昂; (2) 真实性 : 新城市主义形式制造了教条 式的景观；（3）民主性：只存在有限公众参与和私人选择的 需要; (4) 多样性: 仅仅是一种范式, 仅代表了标志阶层和 身份的一种方式; (5) 公正性 : 仅关注建筑观景和改善房地 产价值, 而忽视了贫穷家庭的迁移, 以及对原来社区的干扰 所带来的社会后果 ${ }^{[15]}$ 。

\section{3 形态控制准则}

\section{1 背景}

在新城市主义、断面理论以及绿色建筑理论等场所营造 原则基础上, 规划师们开始发展形态控制准则, 将其作为控 制建成环境的新工具, 希望通过形态引导和设计达到场所营 造的目的, 改变区划带来的诸多弊端。

需要指出的是, 通过形态控制建成环境并不是现代社会 才有的产物。它历史悠久, 可追溯到希波丹姆所规划的米利 都城、中国古代的城市规划, 以及古罗马的城镇规划。以法 规形式出现的形态控制也可以追溯到西班牙王室于 16 世纪 颁布的西印度群岛法律, 而 19 世纪奥斯曼主持的巴黎重建 项目, 通过精确的比例来规定建筑物高度、街道宽度、建筑 立面, 选择一致的行道树和标准化的材质颜色, 以营造一个 统一和谐的公共环境, 被认为是形态控制方面的经典案例。

美国当代形态控制准则发展的标志性事件是 1981 年由杜 安尼和普莱特-齐伯克夫妇及其设计团队设计完成的新城市主 义小区一佛罗里达海滨度假小镇锡赛德 (Seaside), 这个小 区是第一个实施形态控制准则规划条例的社区。经过约 20 年 的发展, 形态控制准则于 2001 年被卡罗尔・怀恩特正式命名, 并得到广泛采纳。图 2 为形态控制准则发展的主要时间节点 示意图。目前, 美国许多城市规划专家都正在推行这一工具, 希望通过形态控制来实现精明增长和场所营造的目标 ${ }^{[24]}$ 。

(1) 1938 年, 美国学者路易斯 - 沃斯 (Louis Wirth) 在《作为一种生活方式的城市主义》(Urbanism as a Way of Life) 一文中站在社会学的角度, 认 为都市环境产生了一种特殊的社会生活, 他将其称为城市主义。 


\section{2 内涵与理念}

作为一种管理土地开发活动的工具, 形态控制准则旨在 创造一个特定的地域类型 ${ }^{2251}$, 强调场所营造和公共空间的管 理与设计。比如, 形态控制准则非常重视街景营造, 关注如 何将街景与私人住房有机联系起来, 如何通过地标建筑提高 公共空间的可识别性以及品质, 如何协调公共建筑物和私人 建筑物的尺度和外观特征, 以及如何减少停车对场所精神的 负面影响等。形态控制准则还强调与社区独特特征契合, 以 形成独特感和归属感。总的来说, 规划师们希望通过形态控 制准则的使用创造一种结构紧凑、混合使用、行人友好的宜 居邻里, 以及健康、充满活力的社区发展模式。

就理念而言, 与传统区划相比, 形态控制准则有如下不 同: (1) 传统区划以控制功能为主, 根据不同功能分区划分 社区, 不鼓励混合使用, 而形态控制准则不再强调功能, 认 为使用功能可能随时间改变, 但建筑本身将持续下去, 将 重心放在形态设计和公共空间营造上, 鼓励多功能兼容;

(2) 传统区划对建筑退后、高度、密度和容积率提出统一 的抽象数据要求, 社区呈现出一种均质性, 而形态控制准则 通过不同横断面分区 (transect zones) 提出不同的建筑标准, 力图使风貌呈现多样化特征, 并追求建筑形式与街景在视觉 和使用上的相得益彰; (3) 传统区划关注的重点是使用功能, 红线内建筑物的形式不可预测, 因而很少或几乎没有关注街 景, 而形态控制准则关注重点街景等公共空间营造, 并通过 对开发方式和建筑形式的规定达到预期规划愿景。

总之, 形态准则强调了形态控制优于功能管制的核心, 以愿景式、说明性的开发规则, 描述 “要求建成什么” 形态, 而不是传统区划采用禁止式条文和抽象参数所带来的 “模糊 形态”。图 3 大致说明了传统区划与形态控制准则在考虑功 能、操作和形态时的秩序与关系。

\section{3 控制内容}

（1）控制性规划 (regulating plan) : 在断面准则基础上, 建立起受控制区域的建筑形式应用及空间类型标准, 其目标 是管理、直接控制和规划。而划分分区边界的标准是依据每
一个分区的开发形态和特征, 即按照横断面所区分的 7 个 由自然地区 (T1) 至城市核心地区（T6）及城市特别分区 (T7) 所呈现的不同分区形态特点来确定。比如, 在辛辛那 提海格立斯 (Hercules) 海湾 FBCs 控制性规划中, 将建筑形 式进一步细化为湾区大道主街建筑、会所、海滨娱乐、一般 性建筑等若干形式, 并对临街建筑提出采用拱廊、沿街前区、 沿河前区、长廊等控制要求。

（2）公共空间标准（Civic Space Standards）：确定公共 领域内各要素的技术规范和参数指标 (如人行道、旅游专线、 路边停车、行道树、街道家具等), 主要涉及通道和市民空间。 具体到通道的控制要求, 会涉及通道的适用范围, 包括交通 类型 (movement style)、设计时速 (design speed)、步行通过 时间。此外, 还会对通道提出一般性要求, 如宽度、转弯半 径、行道树景观布置等。最后通过控制性规划中的横断面形 态对其进行校核, 比如, 在辛辛那提 $\mathrm{FBCs}$ 中, 路缘石设置 仅在 T3-T7 断面分区中抬升, 在 T1、T2 断面分区中并没有 进行具体规定 (表 2)。

(3) 建筑形式标准 (Building Form Standards) : 对建筑 物的结构、特征、功能和退界线等进行控制和规定。主要内 容涵盖分区概述、停车条例、建筑布置条例、建筑形态条例, 许可的土地利用和具体建筑用途的表格、许可临街面类型, 许可突破的尺度、许可的建筑类型。

除此之外, 形态准则还针对需要, 在不同断面增加诸如 地形控制（图 4)、历史建筑和区域、停车要求、建筑高度、 装饰和新建筑兼容性、转角商店样式、特定用途的附加标准等
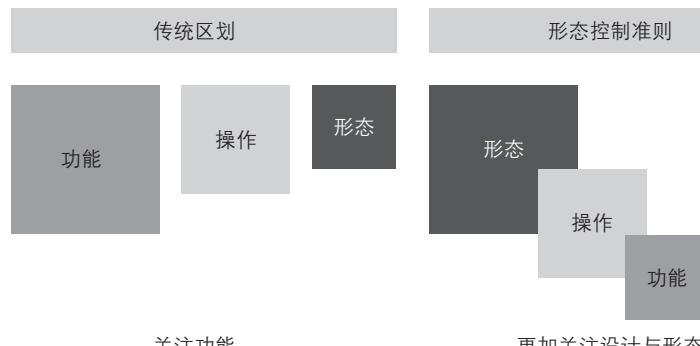

图 3 形态控制准则与传统区划的关注点差异图示 资料来源 : 作者绘制

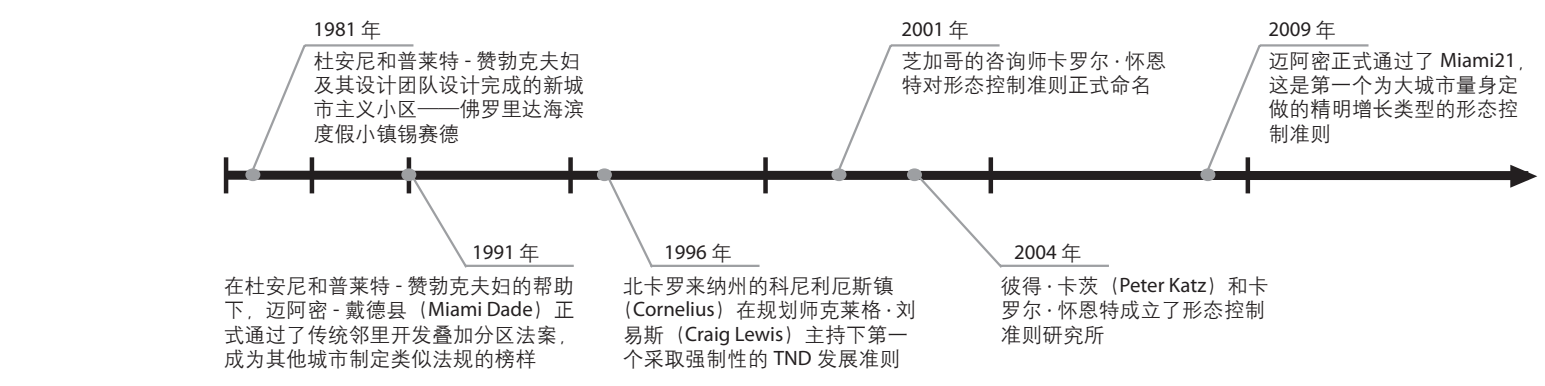

图 2 形态控制准则发展主要节点示意图 资料来源 : 作者绘制 


\begin{tabular}{|c|c|c|c|c|c|c|}
\hline 公共临街类型 & A & B & C & D & $\mathrm{E}$ & $\mathrm{F}$ \\
\hline 断面 & $\mathrm{T} 1 / \mathrm{T} 2$ & $\mathrm{~T} 1 / \mathrm{T} 2 / \mathrm{T} 3$ & T3/T4 & T3/T4/T5 & $\mathrm{T} 4 / \mathrm{T} 5$ & T4/T5/T6 \\
\hline $\begin{array}{l}\text { 路缘石: 车行 } \\
\text { 道边缘的处理 } \\
\text { 方式, 包含管 } \\
\text { 道区域 }\end{array}$ & & & & & & \\
\hline 形式要求 & $\begin{array}{c}\text { 开放半径 10 30 英尺 } \\
\text { (约 3 9 m) }\end{array}$ & $\begin{array}{l}\text { 开放斜道按 } 1: 12 \text { 形成 } \\
\text { 坡道 }\end{array}$ & $\begin{array}{l}\text { 按照 } 1: 12 \text { 提高缘石 } \\
\text { 坡道 }\end{array}$ & $\begin{array}{l}\text { 按照 } 1: 12 \text { 提高缘石 } \\
\text { 坡道 }\end{array}$ & $\begin{array}{l}\text { 按照 } 1: 12 \text { 提高缘石 } \\
\text { 坡道 }\end{array}$ & $\begin{array}{l}\text { 按照 } 1: 12 \text { 提高缘石 } \\
\text { 坡道 }\end{array}$ \\
\hline
\end{tabular}

资料来源 : 参考文献 [26]194

方面的控制内容。总之, 形式控制准则采用了图示化语言, 明 确了不同分区类型下, 特别是对地块层面建设的形态要求。可 以说, 它超越了区划的狭隘、抽象、模糊、不可预知的形态内容, 以物质空间为手段, 实现了新城市主义的理想空间形态。

\section{4 评价}

评价形态控制准则可以从有效性、可行性、效率和公平 等方面展开。有效性方面, 依据目前文献来看, 形态控制准 则对以下三方面有效 : 改善社区的空间形态 ; 培育高质量的 公共领域; 通过 “场所营造” 原则来实现社会愿景目标。当 然, FBCs 是否真正有效还要依赖于规划部门的实施策略和 经验。可行性方面, 希特考斯基和奥姆（Sitkowski \& Ohm） 曾指出形态控制准则具有法律授权，不容易引起法律方面的

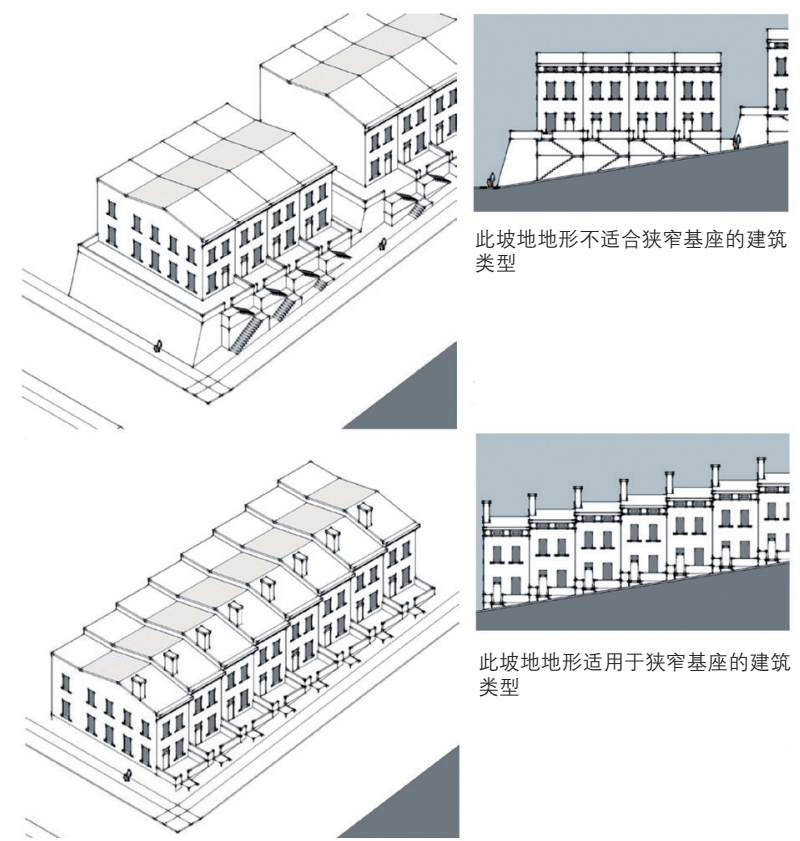

注: 上图为反例, 下图为推荐案例, 以此说明建筑布局需要结合坡地特征。 图 4 特殊地形条件下对建筑的控制要求 资料来源 : 参考文献 [26]134
纠纷, 在政治可行性方面没有太多分歧意见 ${ }^{[25 !}$ 。但是行政管 理方面, 根据博耶（Boyer）的调查结果, 相关规划人员和监 管董事会强制执行和管理形态控制准则的能力值得怀疑 ${ }^{[27]}$ 。 在财政上, 尽管形态控制准则的支持者声称比传统区划更节 约成本, 但缺乏相关证明。同时, 根据博耶的研究, 有三分 之二的社区表示, 开发商的诉求与形态控制管理之间存在着 一定的矛盾 ${ }^{227}$ 。效率方面, 形态控制准则的支持者声称形态 控制准则比传统区划具有更高的行政管理效率。然而, 博耶 的调查结果表明情况并非总是如此, 这一准则的管理被规划 人员和监管董事会认为是繁琐的 ${ }^{[27]}$ 。此外, 在起草形态控制 准则之初, 其审批程序需要大量的时间和资金。而在公平方 面, 形态控制准则可能具有优势, 虽然也可能存在腐败和歧 视问题, 但是, 它相对于传统区划所限定的空间更加具体和 明确, 在自由裁量方面的空间则较少。

总体而言, 形态控制准则试图通过形态控制形成良好的 城市结构和社区氛围，是对美国传统区划带来的各种弊端的 有力回应。作为一种新兴的开发管理工具, 尽管在可行性及 效率等方面还有待实践检验, 但却是有益的尝试。

\section{4 美国城市形态控制的启示}

美国城市形态控制与调整工具发展对我国城市规划具有 以下启示。

（1）从城市发展理念上来看, 应强调功能混合, 注 重微观层面的场所营造, 塑造具有特色的公共空间和城市 风貌。

当前, 我国一些城市也出现了功能单一、组团隔离、交 通拥堵和资源浪费等城市问题, 因此, 应强调功能混合, 重 视居住与就业平衡, 以形成结构紧凑、混合和高效利用的可 持续城市发展模式。另一方面, 我国正处于快速城镇化时 期 ${ }^{[28]}$, 城市发展也存在地方特色丧失、空间均质化、公共空 间缺失以及环境品质低下等问题, 相应地, 尊重基地文脉和 地方特色, 注重场所营造, 塑造具有特色的公共空间和城市 
风貌将成为城市发展的重点。令人欣慰的是, 2015 年底召 开的《中央城市工作会议》及之后由国务院颁布的《关于进 一步加强城市规划建设管理工作的若干意见》都强调了对城 市形态和空间品质的要求。

（2）从城市形态控制手段来看，应重视发展适合我国的 城市形态引导与控制工具。

除了探索城市发展理念, 手段和工具发展也是城市形态 控制的难点和重点。尽管我国目前已经形成以控规为核心的 开发控制体系, 但由于控规对城市形态和空间考虑往往不够 周全, 造成功能单一、尺度偏大、公共空间缺乏和特色丧失 等问题。针对这一现状, 可以借鉴美国精明准则和形态控制 准则等城市形态控制工具, 发展适合我国当前快速城镇化过 程中城市形态与空间控制工具。

（3）从规划行业发展角度来看, 应警惕规划与其他学科 跨界融合中放弃形态设计的传统。

近年来, 我国城乡规划非常重视与地理学、经济学、政 治学以及社会学等学科相结合, 以实现理论嫁接和创新的目 的, 丰富了城乡规划的研究内容, 对我国城乡规划实践和研 究大有裨益。然而, 也正是这种大量的理论嫁接, 造成对城 市形态与空间等城乡规划学科传统领域的忽略, 呈现一定程 度上的理论空心化 ${ }^{[27]}$ 。纵观美国城乡规划理论发展, 1960 年代一1970 年代也强调以社会规划为核心的理论研究 (如 倡导性规划和沟通规划等), 以至于城市形态与空间研究在 一定程度上被忽视。而新城市主义的兴起, 在一定程度上回 归了对城市形态与空间研究的传统, 从而推动了城乡规划行 业的持续发展。因此, 我国应避免过于强调跨学科研究和理 论嫁接而忽视传统领域对城市空间形态的研究。

\section{5 结语}

美国规划界针对区划带来的城市曼延、功能单一以及特 色丧失等问题, 先后提出了新城市主义、精明准则和形态控 制准则等形态控制理念或工具, 期望能够扭转现有城市发展 方式, 最终形成可持续的城市空间形态和模式。针对我国快 速城镇化时期出现的城市形态、风貌和空间等方面的问题, 城乡规划界应在城市发展理念、城市形态与空间控制工具, 以及行业发展等方面做出应对, 发展出适合我国城市可持续 发展的形态引导和控制的理论与工具。UP

\section{参考文献}

[1] 章征涛, 宋彦. 美国区划演变经验及对我国控制性详细规划的启示 [J]. 城市发展研究, 2014, 21(9): 39-46.

[2] 戚冬瑾, 周剑云. 基于形态的条例——美国区划改革新趋势的启示 [J]. 城市规划, 2013, 37(9): 67-75.

[3] FARR D. Sustainable urbanism: urban design with nature[M]. Wiley, 2008: 33.
[4]尼格尔・泰勒, 李白玉, 陈贞. 1945 年后西方城市规划理论的流变 [M]. 北京: 中国建筑工业出版社, 2006: 37-52.

[5]侯丽. 美国 “新” 区划政策的评介 [J]. 城市规划学刊, 2005(3): 36-42.

[6] KAISER E J, GODSCHALK D R. Twentieth century land use planning: a stalwart family tree[J]. Journal of the American Planning Association, 1995, 61(3): 365-385.

[7] DAVIS M. City of quartz: excavating the future in Los Angeles[M]. New edition. Verso, 2006.

[8] GARREAU J. Edge city: life on the new frontier[M]. Knopf Doubleday Publishing Group, 2011.

[9] MIHELICH J. Behind the gates: life, security, and the pursuit of happiness in fortress America by Setha Lowe[J]. American Anthropologist, 2006, 108(3): 601-602.

[10] CALTHORPE P. The post-suburban metropolis[J]. Whole Earth Review, 1991(Winter): 44-51.

[11] CALTHORPE P. The next American metropolis: ecology, community, and the American dream[M]. Princeton Architectural Press, 1993.

[12] KATZ P, SCULLY V J, BRESSI T W. The new urbanism: toward an architecture of community[M]. McGraw-Hill, 1994: 285-300.

[13] URBANISM C F T N. Charter of the new urbanism[J]. Bulletin of Science, Technology \& Society, 2000, 20(4): 339-341.

[14] CALTHORPE P, FULTON W B. The regional city: planning for the end of sprawl[M]. Washington, D.C.: Island Press, 2001: 31-42.

[15] GRANT J. Planning the good community: new urbanism in theory and practice[M]. Taylor \& Francis, 2005: 175-203.

[16] BURAYIDI Michael A. Culture, urbanism and planning[J]. Journal of the American Planning Association, 2006, 75(1): 103-103.

[17] GRANT J L. Theory and practice in planning the suburbs: challenges to implementing new urbanism, smart growth, and sustainability principles[J]. Planning Theory \& Practice, 2009, 10(1): 11-33.

[18] GRANT J. Exploring the influence of new urbanism in community planning practice[J]. Journal of Architectural and Planning Research, 2003, 20(3): 234-253.

[19] HEBBERT M. Engineering, urbanism and the struggle for street design[J]. Journal of Urban Design, 2005, 10(1): 39-59.

[20] KENNY J T, ZIMMERMAN J. Constructing the 'genuine American city' : neo-traditionalism, new urbanism and neo-liberalism in the remaking of downtown Milwaukee[J]. Cultural Geographies, 2004, 11(1): 74-98.

[21] FORD L R. Lynch revisited: new urbanism and theories of good city form[J]. Cities, 1999, 16(4): 247-257.

[22] GRANT J. The ironies of new urbanism[J]. Canadian Journal of Urban Research, 2006, 15(2): 158-174

[23] MARSHALL A. How cities work: suburbs, sprawl, and the roads not taken[M]. University of Texas Press, 2000: 51-134.

[24] COLE R. Form-based codes: a guide for planners, urban designers, municipalities, and developers[J]. Journal of the American Planning Association, 2008, 75(1): 91-92.

[25] SITKOWSKI R J, OHM B W. Form-based land development regulations[J]. Urban Lawyer, 2006, 38(1): 163-172.

[26] OPTICOS DESIGN I. Form-based code - best practices report[R]. City of Cincinnati, Ohio, 2010: 2.

[27] BOYER M. Form or fluff? Assessing the proposed advantages of form-based codes for municipalities[D]. The University of North Carolina at Chapel Hill, 2010.

[28] 章征涛, 李世龙. 城市化的虚荣——对我国城市化现状的认识 [J]. 城市 发展研究, 2011, 18(12): 1-6.

[29] 吴志强.世博规划中关于 “和谐城市” 的哲学思考 [J]. 时代建筑, 2005(5): 18-23.

(本文编辑：张祎娴) 